\title{
Голочалова И.Н.
}

\section{КОНЦЕПЦИЯ РАСКРЫТИЯ ИНФОРМАЦИИ О КАПИТАЛЕ В ФИНАНСОВОЙ ОТЧЕТНОСТИ: ЕЕ КРИТЕРИИ И ДЕЙСТВЕННОСТЬ ПРИМЕНЕНИЯ НА БАЗЕ НСБУ РЕСПУБЛИКИ МОЛДОВА}

\begin{abstract}
Принятие управленческих решений возможно на базе полной информации финансовой отчетности. Для прогноза прироста капитала и принятия решений о повышении эффективности его использования, $и$ привлечения новых инвесторов необходима информация не только об изменении размера капитала, но и о причинах, их обусловивших. В основу Отчета об изменениях капитала положена концепция раскрытия информации о капитале, являющаяся составной частью современной конщепции бухгалтерского учета Концепции МСФО. Отдельными юрисдикциями формат отчета ориентирован на национальные традиции подготовки отчетности, тогда как тенденции современной методологии бухгалтерского учета игнорируются. Примером такого отчета является Отчет об изменениях собственного капитала, входящий в состав финансовой отчетности, регламентируемой нормативной базой Республики Молдова (РМ). В рамках данного исследования автором раскрывается суть концепции представления информации о собственном капитале организаџии, и реализаџия ее применения при подготовке финансовой отчетности в соответствии с юрисдикцией РМ.
\end{abstract}

Ключевые слова: собственный капитал, концепции, структура капитала, изменения капитала, методология учета, качественные характеристики, Отчет об изменении капитала

Постановка проблемы. Для достижения цели финансовой отчетности: представления полезной информации для принятия управленческих решений, организации-составители должны представлять не только информацию об экономических ресурсах, но и о причинах, обусловивших их изменения. Поэтому в состав финансовой отчетности включены отчеты, призванные отвечать обозначенной цели, одним из которых является отчет об изменениях в капитале.

Известно, что в балансе, представляется информация о размере капитала в разрезе его компонентов, а в отчете о прибыли и убытках - о доходе отчетного периода вложенного капитала организации. Однако для расчета прогноза прироста капитала и принятия решений о повышении эффективности его использования, и привлечения новых инвесторов, информационного поля баланса и отчета о прибыли и убытках недостаточно. Более того, при переходе к инновационной модели развития экономики для принятия решений такого рода расширение формата представления информации о капитале является: объективным требованием

(C) Голочалова Ирина Николаевна, д.э.н, доцент Департамента бухгалтерского учета и экономической информатики, Государственный университет Молдовы, г. Кишинев, Республика Молдова, тел. +373602875373, e-mail: monomah5@yandex.ru для организаций сектора крупного бизнеса; для организаций сектора крупного бизнеса; необходимым условием для организаций сектора малого бизнеса.

Однако неопровержимо и то, что отдельными юрисдикциями формат отчета об изменениях капитала устанавливается исходя из таких факторов как принадлежность к модели бухгалтерского учета, сложившихся традиций его ведения и подготовки финансовой отчетности, уровня экономического развития страны. Это порой приводит к парадоксу с тенденциями, обозначенными современной методологией бухгалтерского учета, аккумулирующей в себе последние достижения, как в области теории капитала, так и финансового менеджмента.

Одним из таких примеров, является Отчет об изменениях собственного капитала, входящий в состав финансовой отчетности, регламентируемой законодательной и нормативной базой Республики Молдова (РМ).

Необходимостью нейтрализации противоречия между современными требованиями к представлению информации о капитале в финансовой отчетности и информационным полем отчета о капитале, подготовленным на базе Национальных стандартов бухгалтерского учета (далее, НСБУ) PM, обусловлена актуальность данного исследования. 


\begin{abstract}
Анализ последних достижений и публикаций. Проблемам подготовки и представления информации о капитале посвящены работы таких известных представителей научной среды как: Александер Д. [1] - с теоретических позиций установления формата представления информации о капитале, Ковтун И. [2] - под аспектом концепции раскрытия информации о капитале, Легенчук С. через призму отображения дохода на капитал в интегрированной отчетности, Соколов Я. - с позиции эволюции теории бухгалтерского учета, Цуркану В. [4], [5] - в контексте развития методологии бухгалтерского учета и применения МСФО, Хорин А. [6] - с точки зрения техники формирования информации о капитале. Тем не менее, существует ряд проблем, которые соотносятся с вопросом унификации форм финансовой отчетности в условиях гармонизации системы бухгалтерского учета.
\end{abstract}

Формулирование целей исследования. Целью данного исследования является изучение концепции раскрытия информации о собственном капитале организации и еe применение при подготовке финансовой отчетности через призму требований методологии бухгалтерского учета, которое будет проведено автором по схеме: характеристика критериев формирования; применимость современной методологией бухгалтерского учета и отчетности методологией МСФО; действенность в системе финансовой отчетности $\mathrm{PM}$, регулируемой НСБУ.

Описание основного материала исследования. Как известно собственный капитал является одним из важнейших объектов учета, поскольку:

- воплощает в себе экономические ресурсы организации, потенциально способные приносить доход при условии их эффективного использования;

- призван отразить гражданско-правовые отношения между вкладчиками в организацию деятельности (собственниками имущества) и организацией (собственником чистых активов), являясь при этом исключительно экономической категорией;

- представляет собой источник обеспечения роста благосостояния его собственников.

Однако представление информации о собственном капитале и его изменениях является достаточно сложной задачей для любой организации-составителя отчетности, поскольку, как отмечает исследователь И. Ковтун «концепция раскрытия информации о капитале до настоящего времени находится на стадии становления и требует надлежащего научного обоснования» [2, с. 442].

Современной методологией бухгалтерского учета признанными критериями, формирующих концепцию раскрытия информации о капитале являются: структурные компоненты собственного капитал; принятая модель учета и отчетности; используемая организацией модель управления капиталом; национальные особенности учетных систем.

Охарактеризуем каждый из обозначенных критериев. В согласно методологии бухгалтерского учета собственный капитал организации представляет собой часть совокупного капитала и является внутренним источником финансирования финансовохозяйственной деятельности образованного за счет: вкладов собственников, право которых на их долю подтверждается паем или акциями; части прибыли полученной и нераспределенной собственникам. Отсюда и два компонента в составе собственного капитала - уставный капитал и нераспределенная прибыль.

Знаковым событием, оказавшим влияние на структуру капитала, послужила разработка теории капитала более известной как концепция поддержания размера капитала. Сегодня уже неопровержим факт того, что эффективность использования вложенного капитала проявляется не только в получении дохода на капитал (прибыли), но и в возможности поддержания его размера, изменяющегося под воздействием рыночных условий. Инструментом демонстрации этого факта в отчетности служит концепция поддержания размера финансового капитала, согласно которой в отчетности следует отдельно отражать часть операционной прибыли, направляемой на поддержание размера вложенного капитала при изменившейся его покупательной способности, и оставшуюся часть, которая трактуется как заработанная организацией прибыль отчетного периода.

Исходя из этого требования, структура собственного капитала должна включать такие компоненты как эмиссионный доход и резервы. Следует отметить, что концепция поддержания размера финансового капитала рекомендована к применению Концептуальными основами подготовки финансовой (далее, Концепция МСФО) [11], а также юрисдикциями различных стран, в том числе и РМ.

Таким образом, в результате сочетания применения теории бухгалтерского учета и экономической теории капитала обозначены следующие его структурные компоненты: акционерный (паевой) капитал, эмиссионный доход, резервы и резервы переоценки, нераспре- 
деленная прибыль.

Принадлежность к одной из двух моделей учета и отчетности (англосаксонской или континентальной) в первую очередь характеризуется ориентированием информации на определенную группу пользователей. При англосаксонской модели к раскрытию информации в финансовой отчетности в целом, и в частности о собственном капитале, предъявляется достаточно четкое требование в отношении ее полноты, что объясняется фактом того, что основной группой пользователей при данной модели являются как собственники капитала (акционеры и инвесторы). Превалирование интересов собственников капитала, причем как реальных, так и потенциальных закреплено в теоретической базе МСФО - Концепции МСФО [11]. При континентальной модели учета, к которой относится система бухгалтерского учета РМ, доминирующей группой пользователей являются кредиторы и налоговые органы, поэтому при раскрытии информации о собственном капитале акцент поставлен на точности еe (правильность) представления, тогда как качественная характеристика полноты играет второстепенную роль.

Логичным представляется анализ следующего фактора, определяющего раскрытие информации о собственном капитале - выбор концепции управления капиталом организации [3, с. 481], в соответствии с которой исчисляется ряд показателей, характеризующих размер собственного капитала на отчетную дату. В этом контексте особое значение приобретает информация об изменениях собственного капитала, обусловленных применением политик: дивидендной, определяющей порядок распределения прибыли и расчетов с собственниками; учетной, при которой изменения возникают при eе модификации и при исправлении существенных ошибок.

Уместно отметить, что применение теории капитала, обусловило эволюцию методологии бухгалтерского учета, и как следствие, системы финансовой отчетности, тогда как использование той или иной концепции управления капиталом влияет на объем представляемой информации о собственном капитале в интересах собственников и менеджмента конкретной организации.

Выше обозначенное является доказательством того, что базовым критерием, положенным в основу установления объема информации о собственном капитале, являются информационные потребности пользователей финансовой отчетности.

Международная практика выработала два способа представления информации об изменениях капитала. Первый - заключается в раскрытии информации о прибыли и убытках, признаваемых как изменение капитала $[1$, с. 216]. Согласно этому способу общее изменение в капитале представляет собой суммарные прибыли и убытки отчетного периода (исключение составляют операций с акционерами/собственниками), которые затем распределяются в соответствии с долями участия собственников в уставном капитале. Поскольку наряду с отсутствием данных об операциях с акционерами, игнорируется раскрытие информации о воздействие этого изменения на другие структурные компоненты собственного капитала - эмиссионный доход, резервы и нераспределенная прибыль, то в отношении этого типа операций к данному формату отчета необходимо раскрытие дополнительной информации. В целом составленный первым способом отчет об изменениях капитала, по сути, является расшифровкой только лишь причин общего изменения его размера за отчетный период.

По мнению автора, на определенном эволюционном этапе становления методологии бухгалтерского учета, когда при подготовке финансовой отчетности доминировал юридический подход, применение такого формата информации было вполне оправдано. Однако при инновационном развитии общества, когда в основу подготовки финансовой отчетности положен экономический подход, а назначение отчетности стало носить социальноэкономический характер (современный этап эволюции методологии учета), объем информации стал определяться исходя из ее уровня полезности при принятии экономически целесообразных решений. В этом контексте приобретает значение каждый компонент собственного капитала, возникновение которого обусловливается определенным экономическим событием: один — является результатом перераспределения прибыли, другой - носит корректирующий характер, а назначенье третьего - поддержание размера капитала. Поэтому стало объективной необходимостью раскрытие информации и о причинах возникновения и о сумме изменения в разрезе каждого компонента собственного капитала. Результатом решения этой проблемы явилась разработка альтернативного способа подготовки отчета об изменениях собственного капитала [1, с. 217].

Достоинством формата подготовленного альтернативным способом является раскрытие в нем двойственной сущности капитала: как совокупности компонентов (юридическая трактовка капитала), как чистых активов 
организации (экономическая трактовка капитала), на стоимость которых влияют различные рыночные факторы. Эти факторы приводят к изменению стоимости либо активов, либо обязательств, а, следовательно, и чистых активов организации. Раскрытие информации о каждом факторе позволяет собственникам увидеть экономическое воздействие каждого из них на прирост капитала в разрезе его компонентов. В этом контексте нельзя не согласится с мнением А. Хорина, который рекомендует алгоритм формирования информации о собственном капитале, включающий следующие шаги [6, с. 58]: установление минимальных требований, вытекающих из юридических норм; раскрытие существенной информации, характеризующей специфику структуры капитала, исходя из организационно-правовой формы субъекта; обеспечение дополнительного раскрытия информации по решению менеджмента.

Подготовленный таким образом отчет об изменениях собственного капитала будет отвечать базовым концепциям современной методологии бухгалтерского учета [4, с. 115]: смешанного баланса, достоверности, управления капиталом.

Подчеркнем, что рассмотренный формат отчета об изменениях капитала, подготовленный альтернативным способом рекомендуется к применению системой МСФО и юрисдикциями ряда стран. Подробно порядок подготовки Отчета об изменениях капитала на базе положений МСФО раскрыт в работе: [5, с. 410416]. Однако в РМ закреплен другой его вариант, поэтому остановимся на нем подробнее.

Одной из характеристик системы бухгалтерского учета и отчетности РМ является ее директивность, и ее ориентированность на потребности кредиторов и налоговых органов. Тем не менее, на пути адаптации системы бухгалтерского учета и отчетности РМ к международным и европейским стандартам ее нормативными актами обозначен тезис: цель финансовой отчетности заключается в представление полезной информации широкому кругу пользователей для принятия ими экономически целесообразных решений в отношении организации-составителя отчетности [8, п. 4]. Для реализации этой цели организация-составитель отчетности должна представлять форма, получившая название Отчет об изменениях собственного капитала (далее, Отчет ИСК). В соответствии с законодательной базой РM порядок подготовки и представления указанного отчета регулируется НСБУ «Представление финансовых отчетов [7, п. 5 (11)].

Согласно положениям указанного стандарта Отчет об ИСК характеризует наличие и изменение в течение отчетного периода собственного капитала, составляющими элементами которого являются: уставный и добавочный капитал, резервы, нераспределенная прибыль (непокрытый убыток), прочие его элементы [8, п. 97]. Таким образом, в целом рекомендованный НСБУ «Представление финансовых отчетов» к раскрытию состав собственного капитала отвечает общепринятым требованиям.

Считаем уместным отметить, что в контексте ассоциации с ЕC Правительство РМ взят ряд обязательств, в том числе в части реформ в области бухгалтерского учета. Результатом исполнения этих обязательств является утверждение нового Закона № 287 «О бухгалтерском учете и финансовой отчетности» (вводится в действие с 01.01.2019 г.) и внесение поправок в действующие НСБУ, которые затрагивают требования в отношении представления информации в Отчете об ИСК. Некоторые из этих поправок носят терминологический характер, а другие методологический характер. Так, понятие «уставный капитал» меняется на «социальный капитал», что является одной из попыток привести в соответствие содержание отчетности с ее социально-ориентированным назначением. Отдельными элементами собственного капитала выделены «премии на капитал» и «резервы переоценки», что является исправлением ранее допущенной ошибки, носящей методологический характер. В результате вносимых поправок расширен состав собственного капитала, который теперь будет представлен шестью элементами. Приведем в таблице 2 элементы собственного капитала согласно действующим НСБУ, и его элементы соответствующие проекту их изменений.

Основанием Отчета об ИСК обозначена формула: по каждому элементу собственного капитала указывается остаток на начало отчетного периода, сумма увеличения и уменьшения в течение периода и остаток на конец отчетного периода [8, п. 99]. Кроме этого, в стандарте содержится требование соблюдения равенства между представленными в Отчете об ИСК остатками элементов собственного капитала на начало и конец отчетного периода, и остатками по соответствующим балансовым статьям [8, п. 101]. Эти требования прямо указывают на тот факт, что исследуемый отчет является только 
Таблица 1

\section{Элементы собственного капитала и их назначение согласно действующим НСБУ и} проекту их изменений*

\begin{tabular}{|c|c|c|}
\hline $\begin{array}{c}\text { Элементы собственного } \\
\text { капитала согласно } \\
\text { НСБУ (2014 г.) }\end{array}$ & $\begin{array}{c}\text { Назначение статей элементов собственного } \\
\text { капитала }\end{array}$ & $\begin{array}{c}\text { Элементы собственного } \\
\text { капитала согласно } \\
\text { проекту НСБУ (с } 2019 \text { г.) }\end{array}$ \\
\hline \multicolumn{2}{|c|}{ Уставный и добавочный капитал по соответствующим статьям [8, п. 104-108] } & Социальный капитал \\
\hline Уставный капитал & $\begin{array}{l}\text { Остатки и изменения долей в уставном капитале, } \\
\text { (собственных акций или других инструментов } \\
\text { собственного капитала по номинальной стоимости) }\end{array}$ & $\begin{array}{l}\text { Зарегистрированный } \\
\text { капитал }\end{array}$ \\
\hline Добавочный капитал & $\begin{array}{l}\text { Остатки и изменения, обусловленные либо разницей } \\
\text { между стоимостью вкладов/изъятий собственников } \\
\text { в уставный капитал субъекта и номинальной } \\
\text { стоимостью долей в уставном капитале }\end{array}$ & $\times$ \\
\hline Неоплаченный капитал & $\begin{array}{l}\text { Остатки и изменения дебиторской задолженности } \\
\text { собственников относительно вкладов в уставный } \\
\text { капитал и дополнительных вкладов на покрытие } \\
\text { убытков прошлых лет }\end{array}$ & Неоплаченный капитал \\
\hline $\begin{array}{l}\text { Незарегистрированный } \\
\text { капитал }\end{array}$ & $\begin{array}{l}\text { Остатки и изменения незарегистрированного } \\
\text { капитала по номинальной стоимости акций (долей), } \\
\text { которые еще не были зарегистрированы }\end{array}$ & $\begin{array}{l}\text { Незарегистрированный } \\
\text { капитал }\end{array}$ \\
\hline Изъятый капитал & $\begin{array}{l}\text { Остатки и изменения долей в уставном капитале, } \\
\text { приобретенных/выкупленных субъектом у своих } \\
\text { собственников }\end{array}$ & Изъятый капитал \\
\hline & & Премии на капитал \\
\hline \multicolumn{2}{|c|}{ Резервы по соответствующим статьям [8, п. 110-112] } & Резервы \\
\hline Резервный капитал & $\begin{array}{l}\text { Остатки и изменения резервов, сформированных } \\
\text { согласно действующему законодательству }\end{array}$ & Резервный капитал \\
\hline Уставные резервы & $\begin{array}{l}\text { остатки и изменения резервов, сформированных в } \\
\text { соответствии с уставом субъекта }\end{array}$ & Уставные резервы \\
\hline Прочие резервы & $\begin{array}{l}\text { Остатки и изменения резервов, сформированных в } \\
\text { соответствии с решением уполномоченного органа } \\
\text { управления субъектов }\end{array}$ & Прочие резервы \\
\hline \multicolumn{2}{|c|}{ Нераспределенная прибыль (непокрытый убыток) [8, п. 114-117] } & Прибыль \\
\hline $\begin{array}{l}\text { Поправки результатов } \\
\text { прошлых лет }\end{array}$ & $\begin{array}{l}\text { Остатки и изменения суммы прибыли (убытка), } \\
\text { возникшие вследствие исправления ошибок, } \\
\text { допущенных в предыдущие годы }\end{array}$ & $\begin{array}{l}\text { Корректировки } \\
\text { предыдущих } \quad \text { периодов } \\
\text { (прибыли или убытка) } \\
\end{array}$ \\
\hline $\begin{array}{l}\text { Нераспределенная } \\
\text { прибыль } \quad \text { (непокрытый } \\
\text { убыток) прошлых лет }\end{array}$ & $\begin{array}{l}\text { Остатки и изменения нераспределенной прибыли } \\
\text { (непокрытого убытка) прошлых лет }\end{array}$ & $\begin{array}{l}\text { Нераспределенная } \\
\begin{array}{l}\text { прибыль } \\
\text { убыток) }\end{array} \quad \text { (непокрытый } \\
\end{array}$ \\
\hline $\begin{array}{l}\text { Чистая прибыль (чистый } \\
\text { убыток) } \\
\text { периода }\end{array}$ & $\begin{array}{l}\text { Чистая прибыль (или чистый убыток) отчетного } \\
\text { периода }\end{array}$ & $\begin{array}{lr}\text { Чистая } & \text { прибыль } \\
\text { (понесенный } & \text { убыток) } \\
\text { отчетного периода }\end{array}$ \\
\hline $\begin{array}{l}\text { Использованная прибыль } \\
\text { отчетного периода }\end{array}$ & $\begin{array}{l}\text { Прибыль отчетного периода, использованная в } \\
\text { течение } \text { этого года согласно решению } \\
\text { уполномоченного органа управления субъекта }\end{array}$ & Использованная прибыль \\
\hline $\begin{array}{l}\text { Результат перехода на } \\
\text { новые НСБУ }\end{array}$ & $\begin{array}{l}\text { Прибыль (или убыток) отчетного периода, } \\
\text { полученная при переходе на новые НСБУ }\end{array}$ & $\times$ \\
\hline \multirow{2}{*}{\multicolumn{2}{|c|}{ Прочие элементы собственного капитала [8, п. 119-121]: }} & Резервы переоценки \\
\hline & & $\begin{array}{l}\text { Прочие } \quad \text { элементы } \\
\text { собственного капитала }\end{array}$ \\
\hline Разницы от переоценки & $\begin{array}{l}\text { Остатки и изменения разниц от переоценки } \\
\text { долгосрочных активов у субъектов, применяющих } \\
\text { модель переоценки согласно МСФО }\end{array}$ & \\
\hline $\begin{array}{l}\text { Субсидии субъектов } \mathrm{c} \\
\text { публичной } \\
\text { собственностью }\end{array}$ & $\begin{array}{l}\text { Остатки и изменения субсидий, переведенных в } \\
\text { собственный капитал, полученных государ- } \\
\text { ственными, муниципальными и другими аналоги- } \\
\text { чными субъектами, от органов публичной власти }\end{array}$ & \\
\hline
\end{tabular}

* Источник: разработано автором на базе [8, пункт. 104-121] 
лишь дополнением к балансу. Ниже представлен

капитала, подготовленный

условной фрагмент Отчета об изменениях собственного организацией - ООО «Адмирал» (табл. 2).

Таблица 2

Фрагмент Отчета об изменениях собственного капитала*

\begin{tabular}{|c|c|c|c|c|}
\hline Показатели & $\begin{array}{c}\text { Остаток } \\
\text { на начало } \\
\text { отчетного } \\
\text { периода } \\
\end{array}$ & Увеличение & Уменьшение & $\begin{array}{l}\text { Остаток на } \\
\text { конец } \\
\text { отчетного } \\
\text { периода }\end{array}$ \\
\hline 2 & 4 & 5 & 6 & 7 \\
\hline $\begin{array}{l}\text { Уставный и добавочный } \\
\text { капитал } \\
\text { Уставный капитал }\end{array}$ & 355400 & 30000 & - & 385400 \\
\hline $\begin{array}{l}\text { Итого уставный и } \\
\text { добавочный капитал }\end{array}$ & 355400 & & 30000 & 385400 \\
\hline Резервный капитал & 50000 & & 30000 & 20000 \\
\hline Уставные резервы & $\times$ & $x$ & $\times$ & \\
\hline Итого резервы & 50000 & $x$ & $\times$ & 20000 \\
\hline $\begin{array}{l}\text { Нераспределенная прибыль } \\
\text { (непокрытый убыток) } \\
\text { Поправки результатов прошлых } \\
\text { лет }\end{array}$ & - & - & 193945 & -193945 \\
\hline $\begin{array}{l}\text { Нераспределенная прибыль } \\
\text { (непокрытый убыток) прошлых } \\
\text { лет }\end{array}$ & 8344338 & $x$ & $x$ & 8344338 \\
\hline $\begin{array}{l}\text { Чистая прибыль (чистый } \\
\text { убыток) отчетного периода }\end{array}$ & - & 2804869 & - & 2804869 \\
\hline $\begin{array}{l}\text { Использованная прибыль } \\
\text { отчетного периода }\end{array}$ & $x$ & $x$ & $x$ & $x$ \\
\hline $\begin{array}{l}\text { Итого нераспределенная } \\
\text { прибыль (непокрытый } \\
\text { убыток) }\end{array}$ & 8344338 & 2804869 & 193945 & 10955262 \\
\hline $\begin{array}{l}\text { Прочие элементы } \\
\text { собственного капитала, из } \\
\text { них }\end{array}$ & $x$ & $x$ & $x$ & $x$ \\
\hline Всего собственный капитал & 8749738 & 2834869 & 223945 & 11360662 \\
\hline
\end{tabular}

*Источник: финансовая отчетность за 2017 г. условной организаџии ООО «Адмирал»

Подчеркнем, что два обозначенных требования носят технический характер, тогда как ключевым моментом при подготовке любой формы финансовых отчетов, в том числе и Отчета об ИСК, является требования соблюдения качественных характеристик: понятности, релевантности, достоверности и сопоставимости. Данное требование носит методологический характер.

Теперь попытаемся охарактеризовать Отчет об ИСК, содержание и форма которого должна отвечать выше перечисленным требованиям. Итак, как обозначено в НСБУ, Отчет об ИСК имеет своей целью раскрытие причин, повлиявших на каждую балансовую статью раздела «Собственный капитал», поскольку в балансе эти статьи содержат данные только по двум позициям: остаток на начало и на конец периода [9]. Суммы факторов отражаются в указанном отчете как увеличение или уменьшение статей собственного капитала.
Однако анализ содержания данного отчета позволяет сделать вывод, что в нем как раз и отсутствуют факторы (причины) изменений, а представлен уже результат воздействия этих факторов в качестве определенной статьи каждого элемента собственного капитала, например, уставный капитал при определенных обстоятельствах принимает форму неоплаченного, или незарегистрированного, или изъятого капитала. Такой же подход сохраняется и для прочих элементов собственного капитала (см. табл. 2), что, по мнению автора, приводит к нарушению таких качественных характеристик как понятность и достоверность. Это первая особенность данного отчета.

Следующей особенностью изучаемого Отчета об ИСК является то, что его вертикальный формат, по сути, является развернутым форматом баланса, и, несмотря на простоту представления информации, снижает его качественное назначение. На первый взгляд отражение элементов капитала 
в отчетности не вызывает практических проблем. Однако, если принимать во внимание, что изменения капитала в значительной степени сопряжены с операциями с финансовыми инструментами, то у организации-составителя отчетности возникнет проблема достоверного представления информации в виду отсутствия адаптированного в практике по данному типу операции алгоритма подготовки информации в системе учета и отчетности РМ. Это третья особенность Отчета об ИСК, обусловленная проблемами действующей методологии бухгалтерского учета в PM. B-четвертых, согласно НСБУ изменения учетных политик и ошибки, выявленные при составлении финансовых отчетов, корректируются и исправляются перспективным способом, и только в случае существенной ошибки осуществляется ретроспективный пересчет сравнительной информации [9, п. 31-35].

На основании вышеизложенного, автор делает вывод о том, что Отчет об ИСК подготовленный на базе НСБУ РМ отличается простотой содержания и упрощенным форматом представления. Однако в этом контексте возникает вопрос, если данный отчет, подготовленный бизнес-единицей, не отвечает интересам пользователей информации о состоянии собственного капитала, для средних организаций упрощенный формат снижает уровень полноты информации, а для большинства организации сектора малого бизнеса необязателен для представления, то для каких организаций тогда он предназначен?

Появление этого вопроса свидетельствует о существующем парадоксе между декларированными требованиями к содержанию исследуемого отчета и директивной его структурой, не отвечающей обозначенным требованиям. По мнению автора, причиной возникшего противоречия является отсутствие национальной концепции бухгалтерского учета, четкого представления сути концепции раскрытия информации об изменениях капитала, базовые компоненты которой раскрыты выше. Следовательно, разрешение противоречия должно носить методологический характер, и лежать в плоскости понимания современной концепции капитала, соблюдения принципов современной методологии бухгалтерского учета и установления оптимального соотношения необходимого и допустимого объема информации для организаций, функционирующих в эпоху инновационного развития общества.

Выводы и перспективы дальнейших исследований. В контексте возрастающей роли социально-ориентированной отчетности особо важной становится полнота представления информации об изменениях капитала. Однако для соблюдения этого требования необходимо четкое понимание сущности концепции раскрытия информации о капитале, определение ее места в концепции подготовки финансовой отчетности и анализ действенности применения, на примере составления отчета об изменениях капитала согласно НСБУ Республики Молдова. Принимая во внимание важность данного исследования, автором: раскрыта суть концепции представления информации о капитале через призму характеристик критериев еe формирования; доказана, как компонента Концепции МСФО, ее применимость современной методологией бухгалтерского учета, выявлено противоречие между требованиями концепции и раскрытием информации в Отчете об изменениях собственного капитала, подготовленного на базе положений НСБУ РМ; аргументирована необходимость пересмотра формата указанного отчета в условиях гармонизации системы бухгалтерского учета.

На базе проведенного исследования автором рекомендуется разработка нового формата Отчета об изменениях собственного капитала, в составе финансовой отчетности подготавливаемой согласно НСБУ РМ. Это следующая проблема, которую следует разрешить.

\section{ПЕРЕЧЕНЬ ИСПОЛЬЗОВАННЫХ ИСТОЧНИКОВ.}

1. Александер, Д. Международные стандарты финансовой отчетности: от теории к практике (пер. с англ.)/Д., Александер, А., Бриттон, Э., Йориссен. - М: Вершина, 2005. - 886 с.

2. Ковтун, И. Концептуальные предпосылки отчетного раскрытия информации о собственном капитале предприятия// Научный журнал «Молодой ученый». - 2001. - №3 (62). - c. 443-448

3. Хендрексен, Э., Теория бухгалтерского учета./ Э. Хендрексен, М. ван Бреда. - М.: Финансы и статистика, 1997,576 с.

4. Цуркану, В. Концептуальные основы формирования баланса организации. В: монографии «Розвиток концепції бухгалтерського обліку на основі інституційних підходів та бенчмаркингу»/ Монографія /В., Цуркану, И., Голочалова/ За заг. ред. д.е.н., проф.. Бутинця Ф.Ф. - Житомир «Рута», 2015. - 395с.

5. Цуркану, В. Составление финансовой отчетности в соответствии с международными стандартами: Учебно-практическое пособие (на сквозном примере)/В. Цуркану, И. Голочалова. Кишинэу: АСАР, 2014,480 с. 
6. Хорин, А. Финансовая отчетность организации: раскрытие основных элементов форм отчетности// Бухгалтерский учет. - 2001. - №8. - с. 57-62

7. Закон №.113-XVI от 27 апреля 2007г. Республики Молдова „О бухгалтерском учете”, с последними дополнениями и изменениями. [Электронный ресурс] - Режим доступа: http://lex.justice.md/ru/324098/ [Дата входа, 18 мая, 2018]

8. НСБУ „Представление финансовых отчетов”, утвержденный Приказом Министерства финансов № 118 от 06 августа , 2013. [Электронный ресурс] - Режим доступа: http://www.lex.justice. $\mathrm{md} / \mathrm{viewdoc}$.php?action=view\&view=doc\&id=349175

9. НСБУ „Собственный капитал и обязательства” утвержденный Приказом Министерства финансов № 118 от 06 августа, 2013. [Электронный ресурс] - Режим доступа: http://www.lex.justice.md/ viewdoc.php?action=view \&view=doc\&id=349175

10.НСБУ „Учетные политики, изменения в бухгалтерских оценках ошибки и последующие ошибки” утвержденный Приказом Министерства финансов № 118 от 06 августа , 2013. [Электронный ресурс] - Режим доступа: http://www.lex.justice.md/viewdoc.php?action=view\&view=doc\&id=349175

11. Conceptual Framework for Financial Reporting [online], Available at: [Электронный ресурс] - Режим доступа: http://www.ctcp.gov.co/_files/documents

\section{REFERENCES}

1. Alexander, D., Britton, A. and Iorissen, E. (2005). Mejdunarodnie standarty finansovoy otciotnosti: ot teorii k practice [International Financial Reporting Standards: from theory to practice], (V. Babkin, T. Sedova, trans.). Moscow: Vershina [in Russian]

2. Hendriksen, El. S., van Breda, M.F. (2000). Teoria buhgalterskogo ucheta [Accounting Theory] (I. Smirnova, trans.). - Moscow: Finance and statistics [in Russian].

3. Horin, A. (2001). Finansovaya otciotnost' organizatsiy: rascrytie osnovnyh elementov form otciotnosti [Financial Statements of entity: disclosure of bases elements of Financial Statements]//Accounting, No. 8, pp. 57-62 [in Russian].

4. Kovtun, I. (2014). Conceptual'nye predposylki raskrytiy informatsiy o sobstvennom capitale [Conceptual premises of presentation of reporting information of stockholders equity of enterprises]//Young Scientist, part IV, No. 3 (62), pp. 443-448 [in Russian].

5. Tsurcanu, V., Golochalova, I. (2015). Conceptual'nye osnovy formirovaniy balansa organizatsiy. V: Monografia "Razvitie contseptsiy buhgalterskogo ucheta na osnove institutsional'nyh podhodov I benchmarcinga. [Conceptual framework for the formation of entity balance sheet. In: Monograph «The Evolution of the Concepts of Accounting is based on the institutional approaches and benchmarking»], Zhytomyr: «Ruta», pp. 89-166 [in Russian]

6. Tsurcanu, V., Golochalova, I. (2014). Sostavlenie finansovoy otciotnosti v sootvetstiy s mejdunarodnymi standartami finansovoy otciotnosti [The Preparation of Financial Statements in accordance with International Accounting Standards].Chishinau: AAAP. [in Russian]

7. Zakon No.113-XVI ot 27 apreliy 2007 g. Respubliki Moldova O buhgalterskom uchete [Law No.113-XVI from April 27, 2007 of the Republic of Moldova „On Accounting”, with all subsequent completions and changes]. http://lex.justice.md/ru/324098/

8. Natsyonal'nyi standart buhgalterskogo ucheta „Predstavlenie finansovyh otciotov” [NAS „Presentation of Financial Statements" approved by Order of the Ministry of Finance No. 118 from August 06, 2013]. http://www.lex.justice.md/viewdoc.php?action=view\&view=doc\&id=349175

9. Natsyonal'nyi standart buhgalterskogo ucheta „Sobstvennyi capital i obiyzatel'stva” [NAS „Own capital and liabilities" approved by Order of the Ministry of Finance No. 118 from August 06, 2013]. http://www.lex.justice.md/viewdoc.php?action=view\&view=doc\&id=349175

10. Natsyonal'nyi standart buhgalterskogo ucheta „Uchotnye politici, izmeneniy v buhgalterskih otsenkah, oshibki i posleduiushie sobytiy" [ NAS „Accounting policies, changes in accounting estimates, errors and subsequent events" approved by Order of the Ministry of Finance No. 118 from August 06, 2013]. http://www.lex.justice.md/viewdoc.php?action=view\&view=doc\&id=349175

Одержано 15.09.2018 p. 